CASE STUDY

\title{
Small but Mighty Spelman College Museum
}

June 7, 2018

Liam Sweeney

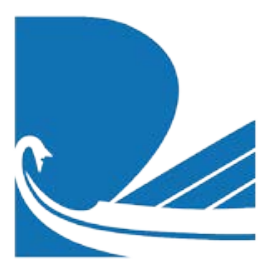

ITHAKA S+R 
THE

ANDREW W.

MELLON

romberion

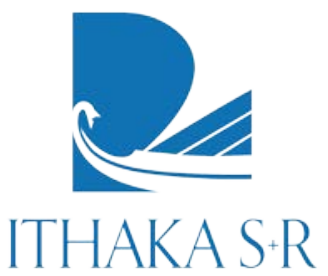

The Andrew W. Mellon Foundation endeavors to strengthen, promote, and, where necessary, defend the contributions of the humanities and the arts to human flourishing and to the wellbeing of diverse and democratic societies.

Ithaka $\mathrm{S}+\mathrm{R}$ provides research and strategic guidance to help the academic and cultural communities serve the public good and navigate economic, demographic, and technological change. Ithaka $\mathrm{S}+\mathrm{R}$ is part of ITHAKA, a notfor-profit organization that works to advance and preserve knowledge and to improve teaching and learning through the use of digital technologies. Artstor, JSTOR, and Portico are also part of ITHAKA.
Copyright 2018 The Andrew W. Mellon Foundation. This work is licensed under a Creative Commons AttributionNonCommercial 4.0 International License. To view a copy of the license, please see http://creative-

commons.org/licenses/by-nc/4.0/.

The Mellon Foundation encourages distribution of the report. For questions, please write to Iw@mellon.org. 
Spelman College Museum of Fine Art is located on the serene campus of a prominent Historically Black College and University (HBCU) in Atlanta, Georgia. A women's institution located in the Atlanta University Center, which also includes Clark Atlanta University, Morehouse College, and the Morehouse School of Medicine, Spelman College is ranked as the top HBCU in the nation by U.S. News \& World Report. ${ }^{1}$ The museum fits neatly within the scope of its host institution; its mission is to present the work of women artists of the African diaspora. In this regard, the culturally specific museum acts as an educational resource where a historically marginalized group of artists are shown without the awkwardness of tokenism, but rather with a deep understanding of cultural production that has been excluded from the art history canon. The expertise this museum has developed in presenting female artists of the African diaspora over the last twenty years is not only a major asset to its parent institution, but also of great value to the field, as will be explored in this report.

In initial discussions with director Andrea Barnwell Brownlee, the question of considering Spelman College Museum within the context of a study interested, at least in part, in representational diversity was raised as a source of some concern. "All my staff are left handed," Brownleejoked. They are also all African American, and mostly female, making Spelman College Museum, in one way of thinking, the most homogenous museum in terms of staff considered in this study.

Studying Spelman College Museum can therefore allow us to focus less on a standard definition of representational diversity and instead on the museum's curatorial practice in relation to the broader field, its ability to make substantial contributions to diversifying the curatorial pipeline, its efforts to realize the museum as an inclusive resource, and its pursuit of institutional partnerships.

\section{Key Findings}

The three-day site visit to Spelman College Museum included fourteen interviews with faculty, staff, students and institutional partners. It also involved tours of Beverly Buchanan-Ruins and Rituals (2017), attending the opening curators' lecture for the exhibition, and observing classes held in the galleries. Several key findings emerged from the visit. In many cases, these findings are relevant to the museum's relationship to its students, as well as the broader public, though strategies for engaging these populations differed.

1 U.S. News College Compass, and see the Historically Black Colleges and Universities Ranking Methodology, "The 10 Best Historically Black Colleges and Universities," U.S. News \& World Report, accessed December 11, 2017, https://www.usnews.com/best-colleges/rankings/hbcu. 
1. Building Partnerships: Collaborations with cultural organizations that share Spelman College Museum's values have allowed for the museum to increase its impact. Staff also see institutional partnerships as helpful in avoiding insensitive or tokenistic curatorial practices.

2. Reaching New Audiences: Integrating with the college's curriculum, as well as connecting with audiences off campus, has allowed the museum to offer new cultural and educational experiences to a variety of communities.

3. Diversifying the Curatorial Field: A commitment to exposing every undergraduate to the museum and its work, along with a targeted curatorial studies program, have contributed substantially towards diversifying the next generation of curators.

\section{Challenges and Tradeoffs}

1. Challenging Assumptions: A young, small gallery on the campus of a women's HBCU, Spelman College Museum has to confront and correct assumptions about who the museum is for and how it operates both on campus and for the broader public.

2. Opportunity Cost: Expectations of job security and social mobility for Spelman students and their parents can act as hurdles to entering the arts, a historically exclusionary, highly competitive field with low starting salaries.

\section{History and Context}

Originally founded by two pioneers in women's education, Harriet E. Giles and Sophia B. Packard, Spelman College was established as a female Baptist seminary for African Americans in Atlanta in 1881. Then known as the Atlanta Baptist Female Seminary, the name was changed when Laura Spelman Rockefeller, who had been active in the antislavery movement, and husband J ohn D. Rockefeller settled the debts for the nascent school. Spelman College became one of six Historically Black College and Universities (HBCU) to form the Atlanta University Center, a consortium of academic institutions that has greatly contributed to the rise of a black middle and upper class in the region, despite the imposition of $\mathrm{J}$ im Crow in the twentieth century. ${ }^{2}$

\footnotetext{
2 Lawrence Otis Graham, Our Kind of People: Inside America's Black Upper Class (New York: HarperCollins Publishers,1999), chapter 14.
} 
In 1929, Spelman oriented itself toward undergraduate curriculum, creating a partnership with Morehouse to allow an access point for black students to pursue graduate study at Atlanta University at a time when they were categorically excluded from research universities. ${ }^{3}$ Throughout the 1950s and 60s many Spelman students participated in the civil rights movement through acts of protest and civil disobedience. ${ }^{4}$ This activism added complexity to Spelman College's reputation at the time as a conservative finishing school. Marian Wright Edelman, who attended despite this reputation, began her social activism with a group of Spelman students and professors, participating in sit-ins and protests. Wright Edelman, founder of the Children's Defense Fund, writes that, "While I hated and hate forced segregation or forced anything, I now recognize that Spelman provided the incubation I needed after leaving home to stand on my feet confidently with anyone anywhere." ${ }^{\prime 5}$ Wright Edelman's perspective of the institution fits with current president Mary Schmidt Campbell's phrase, widely circulated on campus, that "to reach an ideal of equality, Spelman is a necessity." Campbell is practicing what she preaches insofar as she has expanded admissions to include trans women. ${ }^{6}$

In the 1960s Atlanta famously described itself as "too busy to hate," distancing itself from the legacies of $\mathrm{J}$ im Crow in the broader south. However, realtors and city planners employed a number of tactics to ensure functional segregation, even after the civil rights act of 1964 banned segregation and employment discrimination based on race. ${ }^{7}$ While forced-housing patterns were outlawed in the late 1950s, realtors began to commonly practice "blockbusting," a practice of persuading white families to sell their property at low prices by stoking and capitalizing on fears that black families were about to move into the neighborhood. ${ }^{8}$ Realtors then would sell the property at an inflated price to black families who were eager to move out of neighborhoods with poor living conditions, to which they had been circumscribed during the period of legal segregation. The

\footnotetext{
3 Taronda Spencer, "Spelman College," New Georgia Encyclopedia, February 01, 2004, accessed December 14, 2017, http://www.georgiaencyclopedia.org/articles/education/spelman-college.

${ }^{4}$ Harry G. Lefever, Undaunted by the Fight: Spelman College and the Civil Rights Movement, 1957/1967 (Macon, GA: Mercer University Press, 2005).

${ }^{5}$ Marian Wright Edelman, "Spelman College: A Safe Haven for a Young Black Woman," The Journal of Blacks in Higher Education, no. 27 (2000): 118-23, doi: 10.2307/2679028.

6 "Spelman College Becomes Second Women's HBCU to Admit Transgender Women," NBCNews.com, September 11, 2017, accessed December 14, 2017, https://www.nbcnews.com/news/nbcblk/spelman-college-becomes-second-women-s-only-hbcuadmit-transgender-n799536.

${ }^{7}$ Larry Keating, Atlanta: Race, Class, and Urban Expansion (Philadelphia: Temple University Press, 2001).

8 Howard Openshaw, Race and Residence: An Analysis of Property Values in Transitional Areas, Atlanta, Georgia, 1960-1971 (Atlanta: Publishing Services Division, School of Business Administration, Georgia State University, 1975).
} 
combination of private and public efforts to maintain segregation are still felt by city residents. As Victoria Camblin, artistic director of the contemporary arts quarterly publication Art Papers, noted, "In Atlanta there are freeways built specifically to divide communities. The street names change halfway down, from one neighborhood to another. It's been built to segregate. It's hard to get from certain parts of town to others, by design. But the people of Atlanta don't want that. There's a desire for breaking outside of racial divides. People aren't taking it sitting down." By some measures, Atlanta is the second most segregated city in America. ${ }^{9}$

Under the directorship of curator and art historian Andrea Barnwell Brownlee, and a Spelman administration headed by former commissioner of New York City's department of cultural affairs, former Studio Museum in Harlem director, and former dean of NYU's Tisch School of the Arts, Mary Schmidt Campbell, the museum has done much to grow its collection, institutional partners, and program offerings in its twenty-year tenure. Brownlee assumed directorship of Spelman College Museum in 2001, after completing her $\mathrm{PhD}$ in art history at Duke University and a fellowship at the Art Institute of Chicago. As an art historian, she has made significant scholarly contributions to the study of African American art, with texts such as Charles White, ${ }^{10}$ and Cinema Remixed \& Reloaded: Black Women and the Moving Image Since 1970. ${ }^{11}$ As an alumna of Spelman, Brownlee brings a depth of institutional knowledge to her position. It was the museum's mission that drew Brownlee back to Atlanta. "A lot of people assume that I'm here out of nostalgia," she said. "I'm not saying it doesn't play a part, but not as consciously as the mission. If there were other institutions that were as committed to works by and about black women we'd be having a different conversation."

\section{Culturally Specific Mission}

Spelman College Museum's mission can seem narrow at first, sometimes even to stakeholders. Curator of Collections Anne Collins Smith said, "I remember when I came here I wondered, can we really present that specifically?” The concern that audiences within and outside the college might consider the scope too narrow is valid; much work is necessary for culturally specific organizations to reach audiences outside the

\footnotetext{
${ }^{9}$ Nate Silver, "The Most Diverse Cities Are Often The Most Segregated," FiveThirtyEight, May 1, 2015, accessed December 14, 2017, https://fivethirtyeight.com/features/the-most-diverse-cities-are-often-the-most-segregated/.

${ }^{10}$ Andrea D. Barnwell, Charles White: The David C. Driskell Series of African American Art, Volume 1 (San Francisco:

Pomegranate, 2002).

11 Andrea Barnwell Brownlee and Valerie Cassel Oliver, Cinema Remixed \& Reloaded: Black Women Artists and the Moving Image Since 1970 (Houston, TX: Contemporary Arts Museum, 2008).
} 
demographics of their programmatic focus. ${ }^{12}$ In its execution of that work, Spelman College Museum offers its community insights into some remarkable cultural contributions, often overlooked in the broader field.

One interviewee relayed a conversation with a former resident of the Studio Museum Artist in Residence program, Bethany Collins, who described the special environment that emerged in a culturally specific museum, "I could have conversations with my fellow residents that didn't have to start at race. I didn't have to start at the beginning, I could start in the middle." It isn't that identity issues around race and gender disappear when a museum's program is scoped in such a way. Rather, discourse becomes more developed, allowing room for aesthetic discussions that are sometimes ignored when an underrepresented group is shown in a traditionally white space.

Spelman College Museum's mission would be valuable if only to give students a chance to see art made by women of the African diaspora. But by including the broader public, a small 4,800-foot gallery is able to expose the brilliance of many historically marginalized artists to a variety of communities. Soon after beginning to work as a curator at the museum, Smith began to see it as a notably inclusive environment: "Within the context of intersectionality, the great thing is you look at so much more than race. People who are just focusing on race are limiting themselves. Here we offer hospitality as well as rigor."

Kéla J ackson, a student at Spelman participating in The Andrew W. Mellon curatorial fellowship, who has also completed internships at museums in the region, spoke to the distinction. As she puts it, in the broader field, "An emphasis on diversity can seem like a box check, quantitative gain, not about the value of diverse minds coming together to push the museum forward. It doesn't seem like a genuine engagement at times." Because of the scope of mission at Spelman, the kind of tokenism J ackson describes is naturally absent. "Here it's not the same because of how the museum is founded. It doesn't need to scream diversity. We don't have to yell. Others feel that they have to but they don't. It's often an embarrassment, you feel like you're being show ponied. It's an icky feeling because I'm trying to do something I love but I have to do something I didn't sign up for."

12 Chris Elliott, "'(Re)Presenting America": Are Culturally Specific Museums a Good Thing?" People's World, May 15, 2012, accessed December 14, 2017, http://www.peoplesworld.org/article/re-presenting-america-are-culturally-specific-museums-a-goodthingl. 


\section{Achievement through Collaboration}

There are four full time staff of Spelman College Museum: director Andrea Barnwell Brownlee, curator of collections Anne Collins Smith, curator of education Makeba DixonHill, and administrative coordinator Wyatt Philips. Brownlee describes the team as, "Small but mighty." CNN has listed the museum among its "six reasons to love Atlanta." 13 Operating on an international scale, the museum impresses visitors with its high degree of impact and the quality of its exhibitions. For instance, it boasts the distinction of being the only American institution invited to the Havana Biennial. ${ }^{14}$ But no matter how mighty, the staff at Spelman realize they cannot achieve their goals alone. For a museum of Spelman's size and scope, partnerships are essential. In some cases, Brownlee said, these partnerships have allowed Spelman College Museum to bring a unique group of artists to Atlanta. One such case was evident in the exhibition on display in September, Beverly Buchanan-Ruins and Rituals (2017), curated by two independent curators, Park McArthur and J ennifer Burris. ${ }^{15}$ The partnership that resulted in Spelman's hosting and expansion of the exhibition reveals an openness toward collaboration between two culturally specific institutions. Particularly within the context of an educational setting, McArthur and Burris saw a deep level of engagement with the art, enriching their own views of Buchanan's work.

\section{Curatorial Partnerships}

Resulting from McArthur and Burris's research toward a monograph focusing on Buchanan's art, Beverly Buchanan-Ruins and Rituals (2017) was first exhibited at the Brooklyn Museum's Sackler Center for Feminist Art as part of its fiftieth anniversary exhibition series, A Year of Yes: Reimagining Feminism. The exhibition offered an important critique of second wave feminism, addressing some of the ways the movement excluded and alienated people of color. In the context of Spelman College Museum, another layer of significance emerged.

Buchanan moved to Macon, Georgia in 1977, where she produced many of her shack sculptures and land art. In order to bring Ruins and Rituals to Spelman College Museum, Brownlee was interested in including context relevant to her local

\footnotetext{
${ }^{13}$ Doug Gross and Jamie Gumbrecht, "6 Reasons to Love Atlanta," CNN, January 30, 2015, accessed December 14, 2017, http://www.cnn.com/travel/article/reasons-to-love-atlanta/index.html.

14 Through a curatorial partnership with then-CAMH curator Valerie Cassel Oliver: Catherine Fox, "Spelman College Museum Will send 'Cinema Remixed' to Havana Biennial," ArtsATL, June 30, 2012, accessed December 14, 2017, http://artsatl.com/breakingnews-spelman-college-museum-will-send-\%E2\%80\%9Ccinema-remixed\%E2\%80\%9D-to-havana-bienniall.

15 The exhibition was shown earlier in the year at the Brooklyn Museum, and was expanded for Spelman's galleries.
} 
environment. McArthur and Burris responded favorably to this suggestion, allowing the exhibition to evolve as it traveled. Brownlee explained the nature of the collaboration with Brooklyn Museum and McArthur/ Burris, "For us, what became clear was that in order for this particular project to work here, we had to be able to tailor make it to our space from an installation perspective but also in terms of content. Because Buchanan spent so much time in Georgia, we couldn't create a show that wasn't a testament to her time here."

In order for this to work, both institutions needed to be flexible in the ways the show would be adapted. That flexibility granted Spelman and Brooklyn Museum more than either could have achieved individually. In describing Spelman's contributions to the project, McArthur sheds light on the value of interacting local context with the Brooklyn Museum exhibition: "Spelman's careful presentation invited this living exchange between audience and artwork, that much of Beverly's work does so brilliantly in the realms of both personal practice and shared social experience-to be felt, interpreted, and reflected upon. And this was further explored in the series of public and student-focused programs with local poets, activists and organizers, and art historians and visual artists that Spelman put together."

One way in which this shift was felt, particularly at the opening of the exhibition, was in the audience. "There were about twenty hands last night when I asked how many people had a chance to meet Beverly Buchanan," Brownlee says of the crowd opening night. This inevitably creates a more intimate gallery experience - there is a sense of reverence for a local artist, shown in a major encyclopedic art museum, now celebrated back home.

Part of the expanded local context included the museum's educational setting. McArthur shared that in one instance during a class that was being held in the gallery, a student learned of an injury Buchanan sustained to her arm during a sit-in in the early sixties. "After guessing it was her right arm, this student made a connection between Medicine Woman's missing right arm and the torn sleeve on the right arm of the work Church on Fire - a painting from 1995-96 that Beverly made using her studio work shirt. Such close looking and reading blew us away. Spelman's placement of these works, which were essentially looking at one another from the far ends of the long gallery, highlighted this connection that we had not previously thought about." 

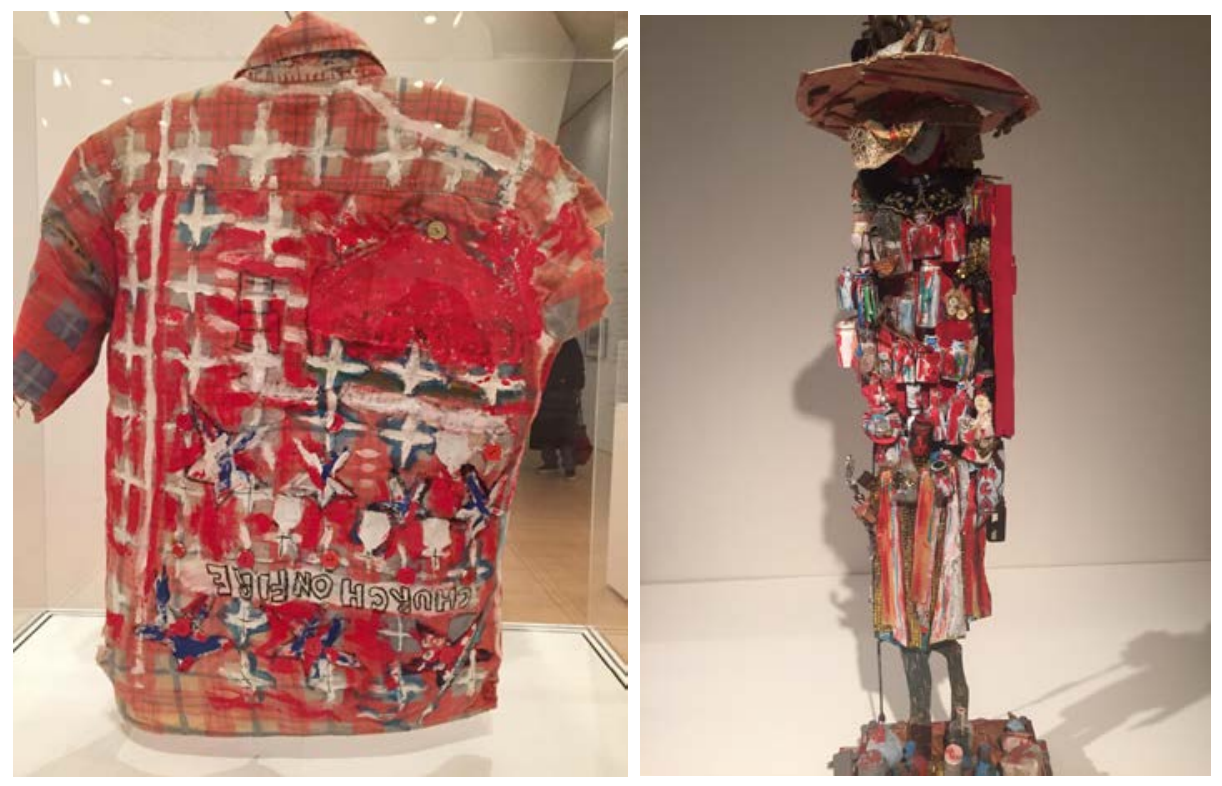

Left: Beverly Buchanan: Untitled, Church on Fire (1995-96) mixed media, Beverly Buchanan-Ruins and Rituals (2017). ${ }^{16}$ Right: Beverly Buchanan: Medicine Woman / Evelyn / The Doctor, 1992, mixed media, Beverly BuchananRuins and Rituals (2017). ${ }^{17}$

In another instance of institutional collaboration, Brownlee and then Contemporary Art Museum of Houston (CAMH) curator Valerie Cassel Oliver co-curated a show called Cinema Remixed \& Reloaded: Black Women Artists and the Moving Image Since 1970, which explored the history of African American women in cinema. ${ }^{18}$ The exhibition received international recognition in the Havana Biennial, which has recognized the contemporary art of Latin America, the Caribbean, and the broader international community since 1984, making them the first American curators to participate. Cassel Oliver describes the exhibition as a response to a body of retrospective works that were celebrating the history of video art: "Many artists left out of the conversation were

${ }^{16}$ Church on Fire (1995-96), which Buchanan occasionally wore while working, responds to the wave of burnings of African American churches in the 1990s. Over 145 black churches were burned from 1995 to 1996, leading to the Church Arson Prevention Act in 1996 and the National Church Arson Task Force under the Clinton administration. Each cross on the shirt represents an incident of arson.

${ }^{17}$ Medicine Woman / Evelyn / The Doctor, reflects the figure of a healer. As stated in the didactic, "The work is reminiscent of bottle trees found across the American South—often created by affixing blue Milk of Magnesia bottles to barren branches. Many people believe that the tradition of placing bottles on tree branches to trap evil spirits originated in Central Africa in the ninth century. Buchanan lived with this work in her home in Athens, Georgia, for the greater part of a decade." In photographs of Buchanan's outdoor studio, digitized by McArthur and Burris, a bottle tree is visible, affirming anecdotal evidence connecting the practice to Medicine Woman for the curators.

18 Sean Carroll, "'Cinema Remixed and Reloaded: Black Women Artists and the Moving Image Since 1970' at Contemporary Arts Museum Houston," Artforum.com, accessed December 14, 2017, https://www.artforum.com/picks/id=21549. 
African American and female. There was no go-to place to look at how black women were dealing with the medium of film. We wanted to bring them together."19

When asked what advice Brownlee has for curators who want to diversify their programs, she suggests the types of collaborations that have grown central to her practice. As she sees it, even if a museum struggles with diversifying its curatorial staff, it can still make changes to its program: “We haven't been as successful as we need to be in getting out of our own way and forging these types of collaborations with people who don't look like us, don't think like us, aren't the same age as our institution." In Brownlee's view, partnerships that allow institutions to learn and expand their cultural lens are essential for avoiding these pitfalls. 'You can form collaborations with people who do or don't look like you, as long as you know you're working toward a common good, meaning offering programming that is going to reach broader audiences." From observing Spelman's institutional partnerships, it is clearly underscored that listening is an important skill for any institution intent on exploring new programmatic territory.

\section{Programmatic Partnerships}

Institutional partnerships are crucial for a small museum to realize an ambitious exhibition program. They are also critical for establishing an atmosphere of inclusion in the museum. When defining its community, the museum "starts with Atlanta," Smith says. "You'll be amazed by who walks through the door." Smith sees the museum as a key factor in bringing diverse audiences onto campus.

The museum faces many barriers to including a broad public in its programming, particularly as a college museum. Saskia Benjamin, executive director of Art Papers, a quarterly contemporary art publication that frequently collaborates with Spelman, explained that "At a university museum, perceived access can be problematic. Sometimes the public doesn't feel that they're welcome on campus. That's part of the thrust for Andrea, as well as for us-to reach new audiences."

This is something that Benjamin recognized as a strength of Brownlee's: "Spelman has much better engagement [than other universities] with communities off campus. The museum makes sure the public knows what's going on. Andrea is prone to collaboration. She thinks about, 'How can we maximize these ideas, who can we partner with?'” Recently, Art Papers, Spelman College Museum, and Atlanta Celebrates Photography partnered to present an Art Papers Live event at the museum gallery, featuring a

${ }^{19}$ Kristin Juárez, "Video: Cinema Remixed and Reloaded 2.0, a Pioneering Trip to Havana, Cuba," BURNAWAY, July 12, 2012, accessed December 14, 2017, http://burnaway.org/feature/video-cinema-remixed-and-reloaded-2-0-a-pioneering-trip-to-havanacubal. 
conversation between artist Mickalene Thomas and Beverly Guy-Sheftall, Spelman professor, and founder of the Women's Research and Resource Center. The conversation was an opportunity for the three organizations to expand and share their audiences. The audiences for Art Papers and Atlanta Celebrates Photography are mostly white. Having a structured partnership to bring these audiences into the Atlanta University Center, the largest HBCU consortium in the country, creates an access point that many would not have found on their own. Brownlee sees these partnerships as an important part of eliminating the, "fear of the unknown" for those who have not attended events on Spelman's campus before. It is this kind of community engagement that Brownlee strives for. "We are extraordinarily proud of our mission," she says, "but we are also rooted in the southern tradition of being welcoming and being hospitable." The practice has yielded lifelong visitors who may have otherwise remained oblivious to the museums presence.

Curator of education Makeba Dixon-Hill is responsible for developing many of these partnerships. As Brownlee explained, "The hiring of a curator of education was critical. It's not only for the educational skill set, but it's about relationships. We needed someone who is very skilled at making those relationships." Dixon-Hill has taken to that role well. "I love whenever Makeba says I'm going to go visit professor x or y because I know that in a short amount of time, something really magical is going to come out of it," Brownlee said. These partnerships can be with faculty, individual artists, and community organizers as well as other organizations. One of her contributions has been introducing "artist guides" to the space. "It's a play on a traditional tour that people get in a museum, but the leaders of these tours are black female cultural producers that are Georgia based," Dixon-Hill says. "They are giving tours in their own style."

These tours enliven the space, embedding it deeper into the local arts environment. Beyond artist guides, the museum has experimented with other programs to reach a broad set of constituents. For instance, they've started a project called BLACK BOX, which allows artists to share in-progress works on the art and culture of the African diaspora in front of a live audience. The program is a dialogue-audiences offer feedback, engagement, and encouragement. Held in the gallery space, connections naturally emerge between the current exhibition and presenter. In the most recent instance of this program, an artist screened a film, "The Possibility of Her," which responds to the same themes as an upcoming exhibition of Deborah Roberts' work, focusing on issues of childhood, race and gender.

The museum has also had success bringing yoga into the galleries. Partnering with Chelsea J ackson Roberts, founder of a community organization called Red Clay Yoga, which uses yoga as an educational tool for youth, marginalized communities, and their allies, the museum has been able to introduce a teen audience to its galleries through a summer camp. The annual Yoga, Literature, and Art Camp, now in its third year, gives 
girls the opportunity to read and discuss texts by authors like Maya Angelou, Nikki Giovanni, and Audre Lorde, as well as to engage with the galleries and their yoga practice.

In addition to the camp, once a week the museum hosts a yoga class in the galleries. Free and open to the public, this program brings a contemplative practice into a space designed for contemplation. Maintaining an hour-long class in the museum creates an access point, and the kind of prolonged exposure to an exhibition that is often necessary to develop a nuanced reaction to a curated show. Brownlee is thrilled that a new group of visitors are treating the galleries as a "micro-retreat."

The spirit of inclusion extends to the way the museum interacts with faculty and curriculum. In the past, Brownlee says the museum was incorrectly thought of on campus as an event space, a good place for a book launch, divorced from its program in some cases. As its reputation has grown, faculty and students now seek it out for its current exhibitions. "What we are really excited about is that if we decide we are going to allow an English class or a performance class to come in, we say we're happy to do this and we love that there's a link to the exhibition. But we also say that we aren't going to close the doors. We're clear that we are about an exchange of ideas. Different people enjoy sitting in on these conversations. To make it a space that is inclusive, we need to invite and embrace that kind of potential."

While community partnerships are essential, Brownlee is particularly committed to growing a sense of familiarity between Spelman's student body and the museum. To do this, she begins with an achievable goal. "We're not trying to suggest that everyone who comes through the museum is going to be a curator or even is going to be frequenting museums necessarily. But we want them to have a regard for museums and visual culture that is going to allow for meaningful lifelong interactions." In this spirit, Brownlee has endeavored toward a goal of making sure each of the 2,140 students engages with the museum in a meaningful way at some stage. Through pairing the museum with the curriculum of a required course, African Diaspora and the World, this goal has been achieved.

\section{Integrating with Curriculum: African Diaspora and the World}

African Diaspora and the World (ADW) is the history requirement for all first-year students at Spelman. It aims to offer students a gender-informed, interdisciplinary perspective on the history and culture of Africa and the African diaspora. In this sense, it seeks to engage students with their identities as global citizens. A two-sequence course, ADW incorporates the museum into the midterm exam, an audio narrative that responds to a piece of art in the museum galleries through the lens of the West African 
philosophical concept àse, the sense of energy or agency present in both living things and sacred objects. ${ }^{20}$

As Smith explains, in ADW students have the opportunity to explore what àse means to them by looking at art work, a requirement that contrasts with the school's more traditional approach to academic achievement. Smith describes the curricular requirement as a respite from resume building: "We're constantly reminded of a familiar maxim here: to whom much is given much is required. The Spelman brand pushes you to be the boss. While you're busy trying to please parents, this is one moment you don't have to do that, you can go off and wonder."

Kéla J ackson, a student at Spelman and recipient of the Mellon Undergraduate Curatorial Fellowship, focused her ADW project on an image from the Black Chronicles II exhibition, which explores black figures from $19^{\text {th }}$ and $20^{\text {th }}$ century England through the lens of Victorian portraiture, aiming to "redress the persistent absence" of dignified black figures in the historical record. ${ }^{21} \mathrm{~J}$ ackson specifically focused on an image of two boys, J ohn Xiniwe and Albert J onas. One is seated, the other is taking his portrait. In the audio narrative, she describes being drawn to this piece, which presents the boys in a dignified way, and gives them a sense of power and agency.

\footnotetext{
${ }^{20}$ As Mikelle Smith Omari-Tunkara writes in Manipulating the Sacred: Yoruba Art, Ritual, and Resistance in Brazilian Candomble, "The most important and sacred phenomenon to survive the transatlantic slave trade and to be shared among Yorùbá in West Africa, people who practice Yorùbá-derived religions in Brazil, and those from other sites in the global Yorùbá diaspora is the belief in the enigmatic and affecting presence of a worldwide energy called àse in Africa, axé in Brazil, and ache in Cuba. Àse is conceptualized as residing in all living beings and inanimate things and operates on many levels—divine, metaphysical, social, and political. Àse as sacred energy and power is found in spiritual entities and human beings as well as in spoken words, secret names, thoughts, blood, animal fur, horns, and tails, bird feathers, art objects, crowns, beaded necklaces, ritually prepared clothing, earth, leaves, herbs, flowers, trees, rain, rivers, mountains, tornadoes, thunder, lightning and other natural phenomena. Àse is used to establish and define shrine buildings or architectural complexes in some parts of Africa as well as in Bahia, where they are known as ilés àse and ilês axés, respectively. [...] As the quintessential commingling of tangible elements, spiritual ideas, and art forms to manipulate the sacred, àse actuates and channels energy or power with respect to sociopolitical, religious, and artistic processes and experiences. For more see: Mikelle Smith, Omari-Tunkara, Manipulating the Sacred: Yoruba' Art, Ritual, and Resistance in Brazilian Candomblé (Detroit: Wayne State University Press, 2005).

21 "Exhibitions," Black Chronicles II | Autograph ABP, accessed December 14, 2017, http://autograph-abp.co.uk/exhibitions/blackchronicles-ii.
} 


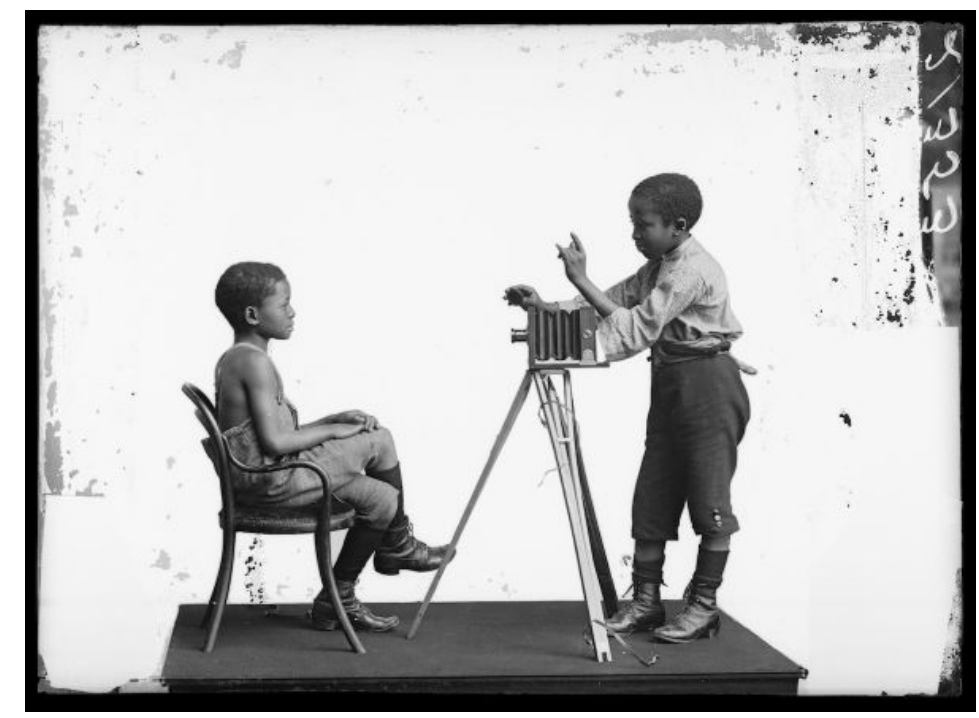

John Xiniwe and Albert Jonas, London Stereoscopic Company studios, 1891. Courtesy of $\odot$ Hulton Archive/Getty Images

J ackson's audio narrative recording is emblematic of over two thousand instances of meaningful interactions with the museum. Brownlee said of the program, "Our goal about four years ago was to make sure that every first-year student had a meaningful experience, something important but very general. We're clear that often times first generation students specifically have not grown up with visual art." At Spelman, about 15 percent of students are first generation. ${ }^{22}$ Over time, Brownlee has seen the impact of this curricular requirement through the increased familiarity students have with the museum: "Now we're several years later, and a group of students comes in and someone says, 'The Howardena Pindell exhibition was the best exhibition,' and someone else says 'No, what was really the best exhibition was so-and-so.'" As Brownlee puts it, they are beginning to develop the "muscle memory" that comes from regular attendance of the galleries, allowing them to draw comparisons and insights and have ownership over what is on view.

From this pool of over two thousand students, Brownlee makes targeted investments in students who show a deep level of interest and talent, in order to provide them with the experience necessary to pursue a curatorial track upon graduation.

\section{Curatorial Pathways}

Mission driven exhibitions, educational programming, organizational partnerships, and student engagement are all critically important to the way Spelman College Museum

22 "Spelman College Fact book," accessed December 14, 2017, https://www.spelman.edu/docs/oirap/2016-17 fact-book wordversion final updated-10-24-17. pdf?sfvrsn=2. 
staff manage their facility. But of special importance to Brownlee is diversifying the curatorial field. It is a frequently discussed topic in many museums now, just as it was in certain circles in the early nineties. As she puts it, "You can do it right, or you can do it again. We've been having this conversation in the field for a long time. We've chosen to do it again." Based on the 2015 Mellon survey, which collected demographic records on over 1,200 curators, African American women accounted for twenty-one of them, less than two percent.

Through Spelman's curatorial studies program, which guides ten students through two years of art history coursework and hands-on curatorial experience, a substantial contribution is being made toward preparing African American students for careers as curators. Funded by The Andrew W. Mellon Foundation, this pilot program grants students access to curatorial studies courses, mentorship opportunities with seasoned curators, and internship opportunities across the country. As Brownlee says, "For me, the next generation piece is critical. We've got more people retiring and passing away than people coming into the field. We're not all necessarily thinking about hiring and pipelining. We need something that is going to take away the excuse of, 'Oh sorry, not enough experience."'

The program, which is available to Spelman, Morehouse, and Clark Atlanta students through a competitive application process, provides access to some exclusive internship opportunities. One student accepted to the program, Cornelia Stokes, progressed through the competitive interview process for the director's internship at the Studio Museum, and worked with Thelma Golden for the summer. Stokes described the internship as the most valuable part of the program. "You can explain how to do something but until you actually do it you don't really understand." The internship opened her eyes to the inner workings of the organization: "It made it more real. As a visitor, you always see the final version but never see what goes into it. You can appreciate it but you don't really know. Every little thing really counts, it matters." Even in her work as an intern, she explained, she felt she made essential contributions to the museum's operations.

Kéla J ackson, whose ADW assignment is mentioned above, completed internships at the Harn Museum of Art at the University of Florida and the High Museum of Art in Atlanta. J ackson is preparing now to apply for master's and doctorate programs in art history. She has learned through these internships that she likes the autonomy that comes from smaller institutions. J ackson is interested in exploring the relationship between "folk" or "self-taught" art and the ways institutions legitimize these works. J ackson focused on folk art in her internship at the High Museum. In her time during the curatorial studies program she has learned something about the way museums effect objects: "Bringing things into the museum gives them validity, but you don't want to lose the essence of the work by bringing it into museum. So there is a balance between integrity and 
legitimizing." As this impression of the relationship between institution and object develops, J ackson gains a skill that is difficult to teach without mentorship and access to the inner workings of museums.

While very few African American women are in curatorial roles in art museums, there are even fewer African American men. Our survey showed that eight African American men were employed as curators in 2015, less than one percent of the total population of curators. Given that the curatorial studies program is open to Morehouse College and Clark Atlanta University, it could also serve as a powerful tool for African American men interested in entering the field. Bu thus far it has primarily been a resource for Spelman students.

To date, one male student has progressed through the curatorial studies program. J ayson Overby, a graduate of Morehouse College matriculated through the curatorial studies program and described it as transformative. "Because of Spelman I walked in with knowledge that others didn't have," Overby said of his internship at the Whitney Museum of American Art. He followed the Whitney with an internship at the Brooklyn Museum. "My [Spelman] teachers made sure I was prepared to know anything. I could walk in and talk about anything. It definitely aligns with Spelman's motto that the women of Spelman go on to change the world. I think they instilled that in me also, because I was their student for four years straight." Now Overby holds a curatorial fellowship at the Louis Armstrong House in Queens and is considering pursuing a Ph.D. in art history.

\section{Opportunity Cost}

Over the course of this study, as well as in previous research investigating trends in art history as an academic discipline, we often heard of the opportunity cost associated with pursuing a career in the arts - an issue, which deeply affects the demographic composition of the field. ${ }^{23}$ At Spelman College, biology and psychology majors accounted for 30 percent of student enrollment in 2016. By contrast, there were 22 art majors, roughly one percent of the student body, a ratio that has held for the last three years. This follows a national trend in higher education in which declining humanities enrollment raises concerns about the market value of traditional liberal arts education. ${ }^{24}$ Research from the Association of Academic Colleges and Universities (AACU) has offered some findings to this effect: "If liberal arts colleges move more closely to the

\footnotetext{
${ }^{23}$ Roger C. Schonfeld and Matthew P. Long, "Preparing for the Future of Research Services for Art History: Recommendations from the Ithaka S+R Report," Art Documentation: Journal of the Art Libraries Society of North America 33 (fall 2014).

24 "Bachleors Degrees in the Humanities," Humanities Indicators, May 2017, accessed December 28, 2017, https://humanitiesindicators.org/content/indicatordoc.aspx?i=34\#fig196.
} 
career-focused mission of comprehensive universities and community colleges or closer to the research mission of elite universities, then the system may lose an important educational option that historically has served many students and the larger society very well. As a consequence, US higher education may become less flexible and less able to meet the educational needs of an increasingly pluralistic society. ${ }^{25}$ Compounded by a dramatic increase in college debt since the report was published in 2012, students who enter the academy without substantial means face difficult financial trade-offs when weighing the value of their degree. ${ }^{26}$

As the AAMD salary survey showed, entry level salaries in the art museum sector are indeed lower than in more commercial sectors. ${ }^{27}$ Because the lack of job security for those with advanced degrees in the humanities privileges the affluent, academic programs interested in diversifying their fields must work to make a case that traditionally excluded populations ought to consider careers in these fields despite financial barriers. ${ }^{28}$ In many instances these cases must be made to the parents of students who want to pursue an art history degree, Brownlee said. She describes some of her students as "closeted art history majors." Their parents insist on a more practical degree if they are to finance an expensive liberal arts education. It will be important to offer parents of students a value proposition for studying arts and culture if these students are to pursue their passion for the arts and enter the field, Brownlee says.

Related to this barrier is the reality that the field broadly relies on networks when hiring, particularly for highly selective positions. Given the importance of networks in gaining access to curatorial positions, creating exposure to curatorial roles in museums is likely to increase the number of students of color interested in pursuing careers as curators. Spelman's curatorial studies program aims to provide this exposure. "We guide them through classroom experiences to consider a profession where they've always been rendered absent," Brownlee said in the inaugural episode of Spelman College Museum's podcast, Be Your Own Muse. ${ }^{29}$ She considers the curatorial studies program a

\footnotetext{
25 Vicki L. Baker, Roger G. Baldwin, and Sumedha Makker, "Where Are They Now? Revisiting Breneman's Study of Liberal Arts Colleges," Liberal Education 98, no. 3 (2012): 48-53.

${ }^{26} \mathrm{Jim}$ Puzzanghera, "Four in 10 Millennials Say They Feel Overwhelmed by Debt, Poll Finds," Los Angeles Times, June 10, 2014, accessed December 28, 2017, http://beta.latimes.com/business/la-fi-millennial-debt-overwhelmed-study-economy-20140610story.html.

27 "Association of Art Museum Directors 2017 Salary Survey," Association of Art Museum Directors, July 3, 2017, https://www.aamd.org/our-members/from-the-field/salary-survey.

28 Yasmine J. Awais and Ann Marie Yali, "Efforts in Increasing Racial and Ethnic Diversity in the Field of Art Therapy," Art Therapy 32, no. 3 (2015): 112-119.

${ }^{29}$ Floyd Hall, "Be Your Own Muse," SoundCloud, Autumn 2016, accessed December 28, 2017, https://soundcloud.com/spelmanmuseum/be-your-own-muse.
} 
meaningful step toward creating the exposure necessary for her students to imagine future careers in museums. "With the opportunities, our students soar. You ask, is the raw talent, the raw interest there? It's there. We just have to craft and mold this clay in ways that we didn't think of before. The talent is here, the opportunity wasn't, until now."

\section{Problematic Donor Relations in Academic Settings}

A recent scandal concerning a major donor to Spelman College has underscored the complexities of problematic donor relations in an academic setting. In 1988, Bill and Camille Cosby, whose two daughters attended Spelman, donated \$20 million to the college. It was the largest single-donor gift to an HBCU at that time. ${ }^{30}$ The gift contributed to the construction of the Camille Olivia Hanks Cosby Academic Center, a four-story structure which houses the museum, as well as the Women's Research \& Resource Center, several humanities departments and an auditorium. The funds were also used to establish the William and Camille Olivia Hanks Cosby Endowed Professorship. After more than sixty women accused Bill Cosby of rape and sexual assault, ${ }^{31}$ the university returned funds for the endowed professorship. ${ }^{32}$ But returning the funds used to construct an academic facility may in some ways be more complicated, because a portion of the gift was used for its construction. Although the gift derives from the fortune that Bill Cosby accumulated from his work in media, the facility is named not for him, but for his spouse. Bearing in mind these factors, Spelman has not renamed the Camille Olivia Hanks Cosby Academic Center.

This incident, which preceded the Harvey Weinstein scandal and the \#MeToo movement, speaks to the ethical quandaries that many administrators of cultural and academic institutions face, as they grapple with complex donor relationships and calls for renaming facilities and endowments. These issues have swept up a number of

\footnotetext{
30 Lee A. Daniels, "A Black College Gets Cosby Gift Of \$20 Million," The New York Times, November 08, 1988, accessed April 23 , 2018, https://www.nytimes.com/1988/11/08/us/a-black-college-gets-cosby-gift-of-20-million.html.

${ }^{31}$ Cosby has since been convicted of three accounts of sexual assault, and faces up to 30 years in state prison. For more on his conviction and a full list of accusations see the following: Chiqui Esteban and Manuel Roig-Franzia, "Bill Cosby's Accusers Now Number 60. Here's Who They Are," The Washington Post, August 3, 2016, accessed May 14, 2018, https://www.washingtonpost.com/graphics/lifestyle/cosby-women-accusers/; Graham Bowley and Jon Hurdle, "Bill Cosby Is Found Guilty of Sexual Assault," The New York Times, April 26, 2018, accessed May 14, 2018, https://www.nytimes.com/2018/04/26/arts/television/bill-cosby-guilty-retrial.html.
}

32 Andrew R. Chow, "Spelman College Terminates Professorship Endowed by Bill Cosby," The New York Times, July 26, 2015, accessed April 23, 2018, https://www.nytimes.com/2015/07/27/arts/spelman-college-terminates-professorship-endowed-by-billcosby.html. 
institutions of higher education, and they are struggling to come to terms with elements of their past, in light of today's growing interest in creating a more inclusive campus environment. ${ }^{33}$ Spelman has assumed an active role in combatting sexual misconduct and assault. ${ }^{34}$ Nevertheless, for a college and a museum that are so focused on inclusion and equity for all people, but especially for its student community of young African American women, grappling with Cosby as both a donor and a building name has been fraught with complexities, both symbolic and tangible.

\section{Conclusion}

As a small gallery with four staff members, Spelman College Museum manages to achieve an impressive impact on the broader field, whether through creating opportunities for its students to pursue a curatorial track, building partnerships to reach a broader public, or working toward revising the canon. Brownlee is keen to give her team credit for their meaningful contributions to the museum's programs and exhibitions. Staff, students and partners alike find her scholarly rigor, radical hospitality, and commitment to transforming the field inspiring. As Victoria Camblin of Art Papers said, "With Andrea, there's this question of how long are we going to get to keep her? She's working on an international level with a small budget."

Internally, Spelman College Museum is able to make a meaningful contribution toward diversifying the curatorial field, which she sees as a central part of role on campus. But externally, Brownlee still sees resistance when leaders consider their own efforts toward diversifying staff and creating more inclusive climates:

I think there's a lot of good will in our field. However, when it comes to inclusion when it comes to diversity, we often create roadblocks, create things like gestation periods. We create reasons why it can't be on the front burner. And there are certain African Americans that are tapped and asked to be on absolutely every board in the city. We don't take initiative to look at younger people. We aren't being honest with ourselves. We want someone who is going to be a 'good fit.' We have all sorts of shorthand for saying that we're not ready. And we've got

\footnotetext{
33 "Yale to Change Calhoun College's Name to Honor Grace Murray Hopper," YaleNews, February 09, 2018, accessed May 14, 2018, https://news.yale.edu/2017/02/11/yale-change-calhoun-college-s-name-honor-grace-murray-hopper-0;

Krystal Knapp, "Princeton University to Rename Building after Toni Morrison, Woodrow Wilson School Auditorium after Arthur Lewis," Planet Princeton, April 18, 2017, accessed May 14, 2018, https://planetprinceton.com/2017/04/18/princeton-university-toname-west-college-after-toni-morrison-woodrow-wilson-school-auditorium-after-arthur-lewis/.

${ }^{34}$ Mary Schmidt Campbell and David A. Thomas, "Our Students Fueled the Civil Rights Movement. This Is What's Next," CNN, April 13, 2018, accessed May 14, 2018, https://www.cnn.com/2018/04/12/opinions/spelman-morehouse-dealing-with-sexual-misconductcampbell-thomas-opinion/index.html.
} 
to get over ourselves. It's not simply about somebody who is going to reinforce your comfort level. When it comes to diversity and inclusion from an HR perspective, from board and leadership perspective, we need to be more honest with ourselves. There are people who are scared, who don't want to do it, who never wanted to do it, and there are some people in the field who don't think it's important, don't think it's a priority, and don't make it a priority for themselves. But on the flip side, there are some people who genuinely want strategies and tools to make extraordinary change for the future, and those are the people who I align myself with.

Small but mighty, Spelman College Museum is enacting meaningful change, and seeking partners and allies who share their goals. 


\section{Appendix}

\section{Case Studies in Inclusion, Diversity, and Equity among AAMD Member Art Museums}

Three years ago, Ithaka S+R, the Andrew W. Mellon Foundation, the Association of Art Museum Directors (AAMD), and the Alliance of American Museums (AAM) set out to quantify with demographic data an issue that has been an increasing concern within and beyond the arts community: the lack of representative diversity in professional museum roles. Our analysis found there were structural barriers to entry in these positions for people of color. After collecting demographic data from 77 percent of AAMD member museums, we published a report sharing the aggregate findings with the public. In her foreword to the report, Mariët Westermann, executive vice president for programs and research at the Mellon Foundation, noted, "Non-Hispanic white staff continue to dominate the job categories most closely associated with the intellectual and educational mission of museums, including those of curators, conservators, educators, and leadership." 35 While museum staff overall were 71 percent white non-Hispanic, we found that many staff of color were employed in security and facilities positions across the sector. In contrast, 84 percent of the intellectual leadership positions were held by white non-Hispanic staff. Westermann observed that "these proportions do not come close to representing the diversity of the American population."

The survey provided a baseline of data from which change can be measured over time. It has also provoked further investigation into the challenges of demographic representation in this sector. Many institutional leaders are growing increasingly aware of demographic trends showing that in roughly a quarter century, white non-Hispanics will no longer be the majority in the United States, whereas ten years ago the white nonHispanic population was double that of people of color. ${ }^{36}$ This rapid growth indicates that institutions will need to be intentional and strategic in order to be inclusive. To aid these efforts we set out to understand the following: What practices are effective in making the American art museum more inclusive? By what measures? How have museums been successful in diversifying their professional staff? What do leaders on issues of social justice, equity, and inclusion in the art museum have to share with their peers?

\footnotetext{
35 Roger Schonfeld, Mariët Westermann, and Liam Sweeney, "Art Museum Staff Demographic Survey," Andrew W. Mellon Foundation, July 29, 2015, https://mellon.org/media/filer public/ba/99/ba99e53a-48d5-4038-80e166f9ba1c020e/awmf museum diversity report_aamd 7-28-15.pdf.

36 William H. Frey, "A Pivotal Period for Race in America," In Diversity Explosion: How New Racial Demographics Are Remaking America (Washington DC: Brookings Institution Press, 2015), 1-20, http://www.jstor.org/stable/10.7864/j.ctt6wpc40.4.
} 
Using the data from the 2015 survey, we identified 20 museums where underrepresented racial/ ethnic minorities have a relatively substantial presence in the following positions: educators, curators, conservators, and museum leadership. We then gauged the interest of these 20 museums in participating, also asking a few questions about their history with diversity. In shaping the final list of participants, we also sought to ensure some amount of breadth in terms of location, museum size, and museum type. Our final group includes the following museums:

- The Andy Warhol Museum (Pittsburgh)

- Brooklyn Museum

- Contemporary Arts Museum Houston

- Detroit Institute of Arts

- Los Angeles County Museum of Art

- Museum of Contemporary Art, Chicago

- Spelman College Museum (Atlanta)

- Studio Museum in Harlem. ${ }^{37}$

We then conducted site visits to the various museums, interviewing between ten and fifteen staff members across departments and levels of seniority, including the director. In some cases, we also interviewed board members, artists, and external partners. We observed meetings, attended public events, and conducted outside research.

In the case studies that follow, we have endeavored to maintain an inclusive approach when reporting findings. For this reason, we sought the perspectives of individual employees across various levels of seniority in the museum. When relevant we have addressed issues of geography, history, and architecture to elucidate the museum's role and context in its environment. In this way we show the museum as a collection of people - staff, artists, donors, public. This research framework addresses the institution as a series of relationships between these various constituents.

We hope that by providing insight into the operations, strategies, and climates of these museums, the case studies will help leaders in the field to approach inclusion, diversity, and equity issues with a new perspective.

\footnotetext{
37 We focused on people of color for measuring diversity for two reasons: (1) In the 2015 art museum demographic study, we received substantive data for the race/ethnicity variable, unlike other measures such as LGBTQ+ and disability status, which are not typically captured by human resources, and (2) in the study we found ethnic and racial identification to be the variable for which the degree of homogeneity was related to the "intellectual leadership" aspect of the position (i.e., curator, conservator, educator, director). We are alert to issues of accessibility in this project, and although it was not foregrounded in our original project plan we hope to address these questions in more depth in future projects.
} 